\title{
Multiobjective FEM based optimization of BLDC motor using Matlab and Maxwell scripting capabilities
}

\author{
R. CARAMia ${ }^{1}$, R. Piotuch $^{2}$, R. Palka ${ }^{2}$ \\ ${ }^{1}$ Department of Industrial and Information Engineering, University of Pavia \\ 27100 Pavia, Italy \\ e-mail: raffaelecaramia@hotmail.com \\ ${ }^{2}$ Department of Power Engineering and Electrical Drives, West Pomeranian University of Technology \\ 70-313 Szczecin, Poland \\ e-mail: \{rpiotuch/rpalka\}@zut.edu.pl
}

(Received: 18.11.2013, revised: 29.01.2014)

\begin{abstract}
The paper presents a methodology for the optimization of a Brushless Direct Current motor (BLDC). In particular it is focused on multiobjective optimization using a genetic algorithm (GA) developed in Matlab/Optimization Toolbox coupled with Maxwell from ANSYS. Optimization process was divided into two steps. The aim of the first one was to maximize the RMS torque value and to minimize the mass. The second part of the optimization process was to minimize the cogging torque by selecting proper magnet angle. The paper presents the methodology and capabilities of scripting methods rather than specific optimization results for the applied geometry.

Key words: permanent magnets excited electrical machines, multiobjective optimization, Pareto Front
\end{abstract}

\section{Introduction}

Nowadays it becomes clear that the electromagnetic devices has to fulfill multiple objectives concurrently [1-5]. The objectives of the optimization are not always the same because they vary with the application in which the device is used [1]. In a multi-criteria optimization (MCO) general solution is represented by a Pareto Front. It represents a list of all non-dominated solutions that allows to fulfill the objectives of optimization. These solutions may be further evaluated by the designer considering mechanical, thermal and technological constraints.

In recent years, compact and highly efficient BLDCs are being increasingly used in many industry sectors in new applications such as robots, electric vehicles, elevators or as alternatives to induction motors in already installed applications [5, 6]. BLDC motors are being manufactured and used increasingly due to their inherent advantages: high efficiency, high torque to mass ratio, low rotor moment of inertia and very simple control systems. Such features can be achieved thanks to the development in the field of materials engineering and 
power electronics. It is of great interest to improve motor geometry by design optimization, thus to reduce production costs and improve performance of motors [1]. The fundamentals of the topology optimization have originally been described in [7, 8]. Increasing capabilities of nowadays tools and packages connected with better performance of computers allowed to achieve good results in the field of electrical machines optimization with a computational cost compatible with the industrial processes [1]. In the last decade, in many fields of engineering, evolutionary algorithms have been applied in order to find properly the Pareto Front $[9,10]$.

The aim of the paper is to present simple optimization capabilities of combined software packages in the field of BLDC motor geometry optimization process.

In the paper [11] it is shown that using unimodal function over one variable (i.e. RMS torque value $T_{r m s}$ ) and multimodal function for the same variable (RMS cogging torque value $T_{\operatorname{cogg}}$ ) leads to not effective operation of the optimization algorithm. Aforementioned problem has been solved thanks to decomposition of the optimization process into two stages described below.

\section{Design problem}

The case of study is represented by a Brushless DC Motor, with a starting parameters as follows: the motor consist of PM type $\mathrm{NdFeB}\left(B_{r}=1.23 \mathrm{~T},-890^{\prime} 000 \mathrm{~A} / \mathrm{m}\right)$ with 3 phase whole-coiled winding (30 conductor per slot). The rated torque of a model is $7.7 \mathrm{Nm}$ (with 5.8 Nm RMS value). Phase current for all models was set to $4.96 \mathrm{~A}$. Main design variables are presented in Table 1. Analyzed basic model with magnetic flux density distribution over a cross-section is depicted in Figure 1.

Table 1. Main design parameters

\begin{tabular}{c|c|c}
\hline $\mathbf{2 p}$ & Number of poles & $\mathbf{4}$ \\
\hline$d_{\text {ostat }}$ & outer diameter of the stator & $130 \mathrm{~mm}$ \\
\hline$d_{\text {istat }}$ & inner diameter of the stator & $72 \mathrm{~mm}$ \\
\hline$l_{\text {as }}$ & stack axial length & $72 \mathrm{~mm}$ \\
\hline$w_{\text {oslot }}$ & width of the slot opening & $2.5 \mathrm{~mm}$ \\
\hline$n s$ & number of slots & 24 \\
\hline$m$ & number of phases & 3 \\
\hline$h_{s l o t}$ & height of the slot & $12.3 \mathrm{~mm}$ \\
\hline$w_{t}$ & width of the tooth & $4.0 \mathrm{~mm}$ \\
\hline$r_{p m}$ & pole angle ratio & 0.5 \\
\hline$t_{m}$ & $\begin{array}{c}\text { magnet thickness } \\
n_{1}\end{array}$ & $\begin{array}{c}\text { number of turns in the single } \\
\text { coil winding }\end{array}$ \\
\hline
\end{tabular}


Fig. 1. Magnetic flux density distribution and flux lines over motor cross section (geometry sample)

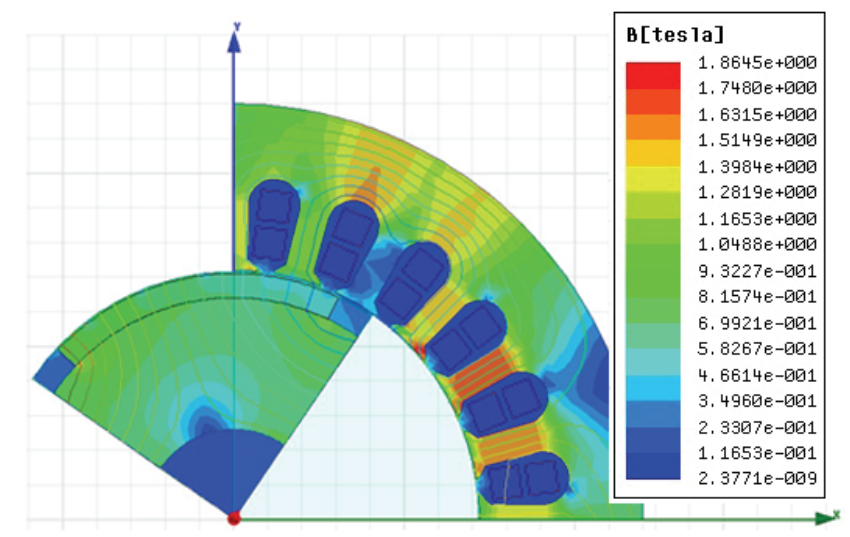

\section{Multiobjective optimization}

Generally multiobjective optimization involves minimizing or maximizing multiple objective functions to a set of constraints. The problem consists of identifying the feasible solutions - for electric motor it is geometries of the machine that maximize the torque and minimize the mass. This set of objectives is of great interest in all optimization problems of modern motors applied in electrical vehicles $[5,12]$, where maximum torque provides maximum acceleration, while minimum weight is necessary in order to reduce energy consumption and lower price of a hybrid or electric vehicle. The following objective functions are defined:

$$
\begin{gathered}
f_{1}(x)=\int_{\Omega} \rho(x) d \Omega, \\
f_{2}(x)=T_{r m s}(x),
\end{gathered}
$$

where $\rho$ is the density of materials. The first relationship represents the mass of the motor that has to be minimized, while the second one represents the RMS torque value that has to be maximized. With regard to the time consumption for the evaluation of the functions, the first one is a geometry dependent function and the cost for its calculation is almost inexpensive, while the torque is field-dependent one and needs many iterations of nonlinear finite element analysis. As mentioned before, there may exist multiple solutions to this problem. After solving the MCO problem a set of optimal non-dominated solutions is generated and Pareto Front is determined. With the information provided by Pareto Front, the motor designer may select a proper geometry, according to his designing experience [1]. The direct problem has been solved using a 2D FE model of the motor; torque has been calculated with the virtual work principle. Even if the shape of the motor changes and the mesh changes for every model, the number of elements of the mesh is almost the same in every model. Meshed geometry and design variables are depicted in Figure $2 \mathrm{a}$ and $2 \mathrm{~b}$, respectively. 
a)

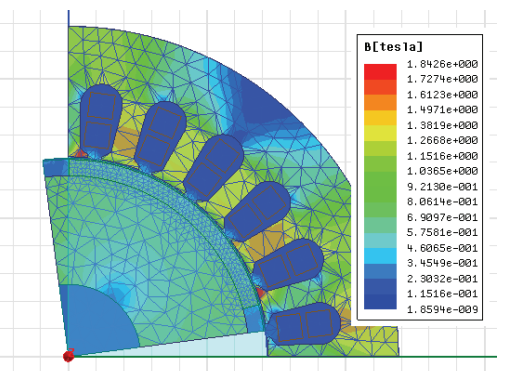

b)

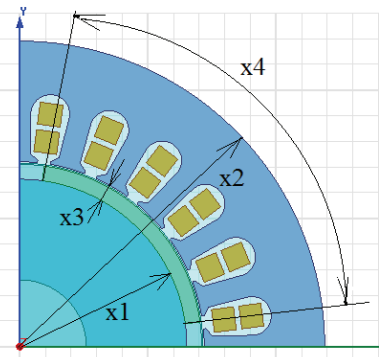

Fig. 2. a) Meshed geometry, b) Design variables

The second part of geometry optimization considers reducing the cogging torque of the motor. Cogging torque arises from the saliency of the stator slot structure for windings, and depends on the magnetization pattern (radial or axial), shape of the permanent magnet and the shape of the core [9]. Minimization of cogging torque is especially important, because low torque ripples cause smaller mechanical distortion and bigger robustness [4, 13, 14]. For example cogging torque in small BLDC motors used in driving systems of digital versatile disk (DVD) or hard disks (HDD) can cause some serious vibration and noise problems [14]. Basic stages of the proposed algorithm are shown in Figure 3.

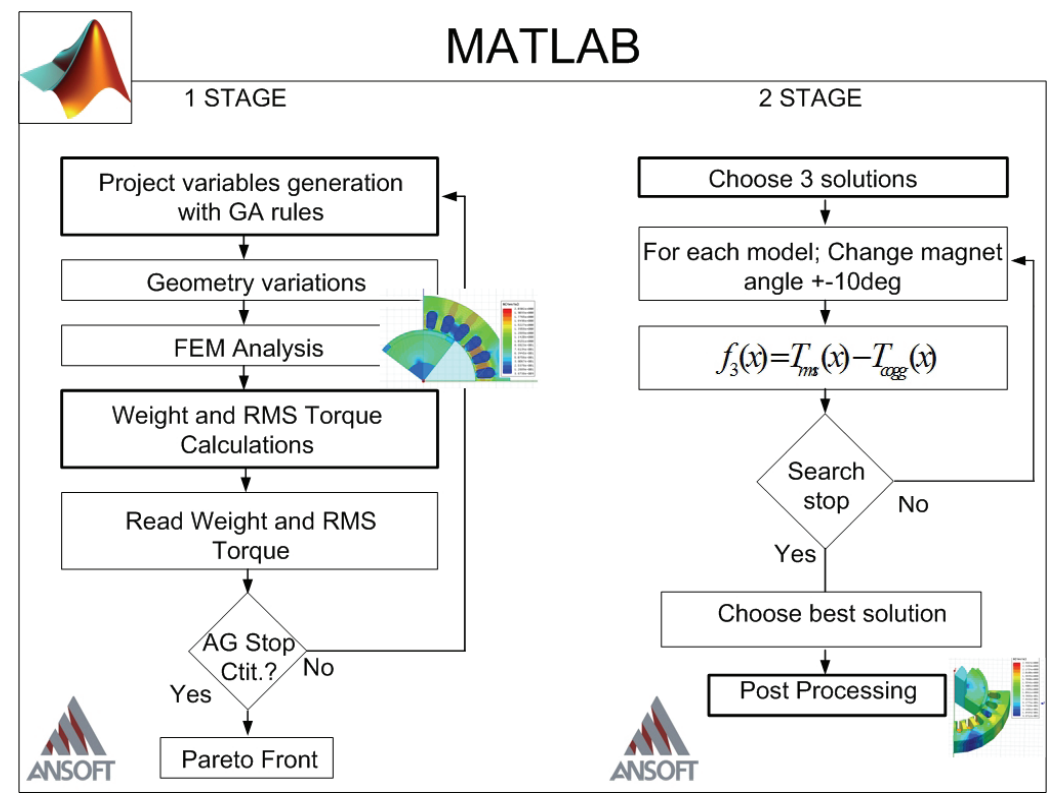

Fig. 3. Optimization algorithm workflow

The second stage of proposed optimization procedure could be applied in the first optimization process but it adds another objective function and may cause serious convergence problems [11]. The first and the final geometries were verified with the 3D FE-model. 


\section{Genetic algorithm setup}

Genetic algorithm is a heuristic technique based on struggle between individuals. Each individual is a possible solution of optimization problem. A common method is to transfer the strongest with the best fitness function from previous population and select other best individuals for mutation and cross-over process [10]. This method mimics natural selection process were the strongest individuals survive but other features that are not important at the time are also passed to next generation in the children genotype.

Matlab's multiobjective genetic algorithm is a variant of Deb's NSGA-II [10] and has different parameters that may be set up by the user. It is possible to define the number of design variables and their upper and lower bounds, constraints of the variables values, the stopping criteria (e.g. maximum generation limit, time limit), the number of individuals for each population, the number of individuals of the Pareto Front etc.

In the case of study all the parameters were left at their default values, with exception of number of variables, stopping criteria (maximum generations number) and number of individuals:

- number of variables: 4 ;

- maximum number of generations: 10 ;

- number of individuals for each population: 60;

- number of individuals in the Pareto Front: 13.

In Table 2 upper and lower boundaries for the variables are reported; the air-gap is kept at the constant level - that is $1 \mathrm{~mm}$.

Table 2. Boundaries for selected design variables

\begin{tabular}{c|c|c|c|c}
\hline $\begin{array}{c}\text { Design } \\
\text { variables }\end{array}$ & $\begin{array}{c}\boldsymbol{x}_{\mathbf{1}}[\mathbf{m m}] \\
\text { Rotor outer } \\
\text { diameter }\end{array}$ & $\begin{array}{c}\boldsymbol{x}_{\mathbf{2}}[\mathbf{m m}] \\
\text { Stator outer } \\
\text { diameter }\end{array}$ & $\begin{array}{c}\boldsymbol{x}_{\mathbf{3}}[\mathbf{m m}] \\
\text { Magnet thickness }\end{array}$ & $\begin{array}{c}\boldsymbol{x}_{\mathbf{4}}[\mathbf{d e g}] \\
\text { Magnet angle }\end{array}$ \\
\hline Lower & 50 & 110 & 0.8 & 45 \\
\hline Upper & 75 & 160 & 3 & 82 \\
\hline
\end{tabular}

\section{Maxwell setup}

In Maxwell environment all the settings were left at the default values that are generated automatically when a $2 \mathrm{D}$ model is created. The analyzed model is just a quarter of motor, because the software sets the proper boundary conditions for the symmetrical calculation problem. The solver is set to 'transient', because the software automatically moves the rotor for defined value. Automatically generated mesh consists of almost 1800 elements. Some simulations were run in order to check if a higher number of elements of the mesh could affect the torque waveform; the result was that the waveform is almost the same even with higher number of elements. Considering that, the whole algorithm creates 660 models; it is useful to keep the low number of elements if possible, in order to achieve the low computational time. Every FE analysis lasted for 20 seconds (for the first optimization stage for the i7 $3.6 \mathrm{GHz}$, 
8 GB RAM, PC), so the whole optimization process lasted approximately $20 \mathrm{~s} \cdot 660=13$ '200 s. For the cogging torque calculation, in order to have a smoother waveform, the mesh was substituted with another one made of almost 6000 elements. Of course, it is possible to change the density of the mesh, changing proper mesh parameters.

\section{Results - first optimization stage}

The first result generated by Matlab is Pareto Front, a graph that shows a family of nondominated solutions. The designer should choose the optimal solution from this graph. There is not a model that is absolutely better than the others, all of them are feasible and selection can be made taking into account other features that the motor should have. Figure 4 shows the Pareto Front obtained during the $1^{\text {st }}$ optimization process stage. As it can be seen, a general reduction of dimensions (mass) of the motor is obtained; interesting result is an increase in the dimension of PMs, because it implies consequently, an increase of the motor cost.

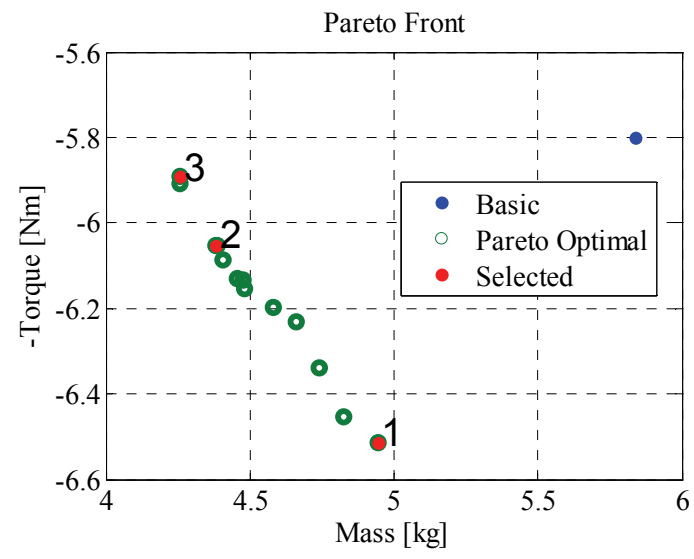

Fig. 4. Pareto Front calculated in the $1^{\text {st }}$ optimization stage

For the next optimization stage three indicated solutions from the Pareto Front were chosen. Table 3 shows design variables values for the 3 selected and the basic geometry. Figure 5 shows cross section of proposed motor geometries.

\section{Results - second optimization stage}

The next optimization stage is to minimize $T_{\text {cogg }}$ and maximize $T_{r m s}$. Figures $6 \mathrm{a}$ and $6 \mathrm{~b}$ show the waveforms of the cogging torque in an arc of the stator slot pitch for the 3 prototype models and basic geometry. 
1
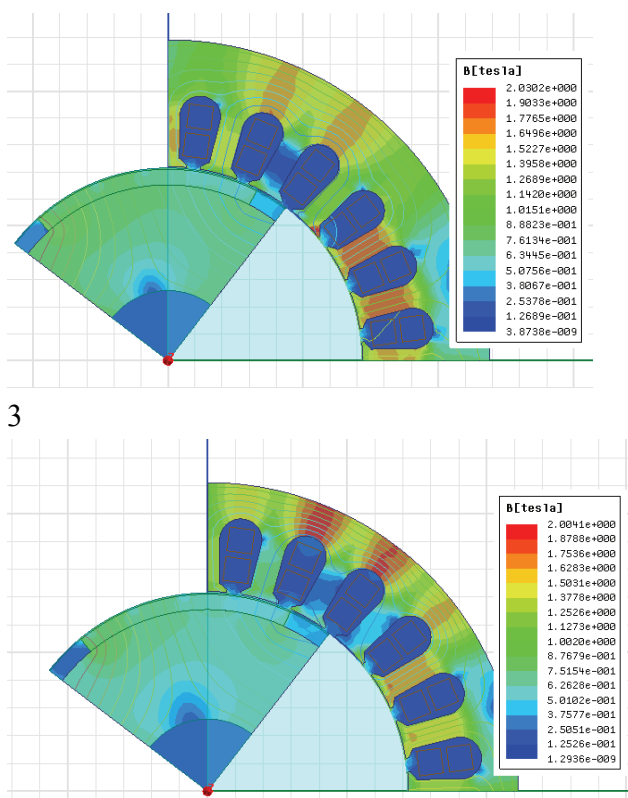

2

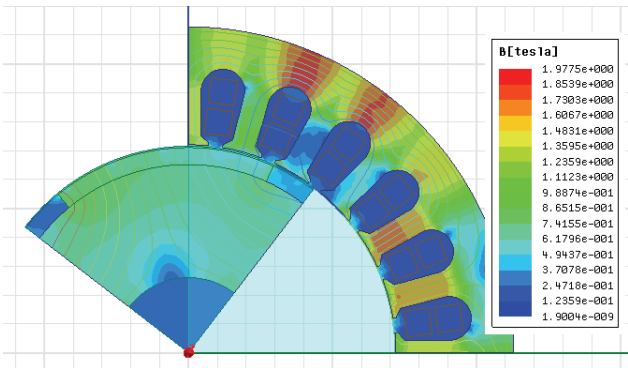

Basic

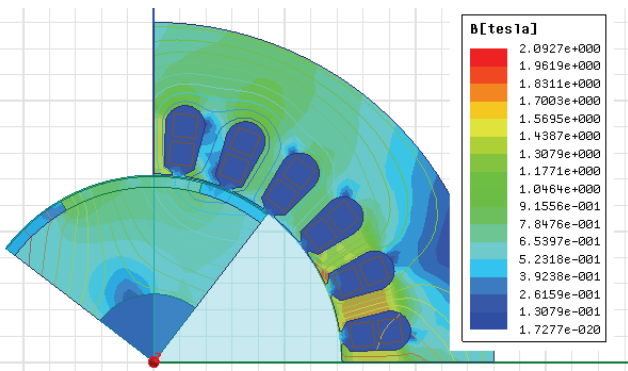

Fig. 5. Comparison of selected geometries; magnetic flux density distribution and flux lines Table $3.1^{\text {st }}$ optimization stage results

\begin{tabular}{c|c|c|c|c|c|c|c}
\hline Model & $\begin{array}{c}\boldsymbol{x}_{\mathbf{1}}[\mathbf{m m}] \\
\text { rotor outer } \\
\text { diameter }\end{array}$ & $\begin{array}{c}\boldsymbol{x}_{\mathbf{2}}[\mathbf{m m}] \\
\mathbf{s t a t o r} \\
\text { outer } \\
\text { diameter }\end{array}$ & $\begin{array}{c}\boldsymbol{x}_{\mathbf{3}}[\mathbf{m m}] \\
\text { magnet } \\
\text { thickness }\end{array}$ & $\begin{array}{c}\boldsymbol{x}_{\mathbf{4}}[\mathbf{d e g}] \\
\text { magnet } \\
\text { angle }\end{array}$ & $\begin{array}{c}\text { Mass } \\
{[\mathbf{k g}]}\end{array}$ & $\begin{array}{c}\boldsymbol{T}_{\boldsymbol{r m s}} \\
{[\mathbf{N m}]}\end{array}$ & $\begin{array}{c}\boldsymbol{T}_{\boldsymbol{c o g g}} \\
{[\mathbf{N m}]}\end{array}$ \\
\hline Basic & 65.0 & 130.0 & 2 & 45 & 5.84 & 5.8 & 0.20 \\
\hline Pareto optimal 1 & 69.7 & 119.0 & 2.89 & 70 & 4.95 & 6.51 & 0.71 \\
\hline Pareto optimal 2 & 67.6 & 112.8 & 2.93 & 64 & 4.38 & 6.05 & 0.53 \\
\hline Pareto optimal 3 & 67.2 & 111.2 & 2.77 & 64 & 4.26 & 5.89 & 0.60 \\
\hline
\end{tabular}

a)

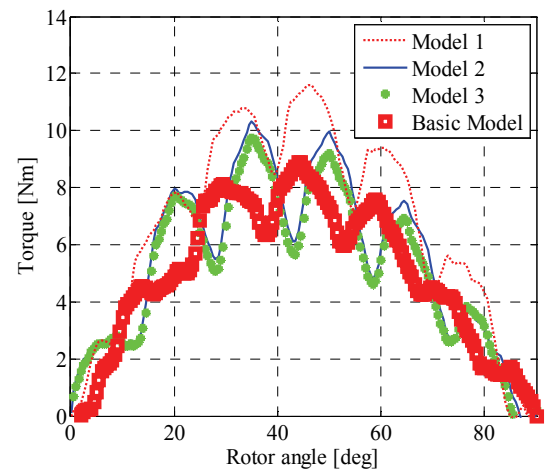

b)

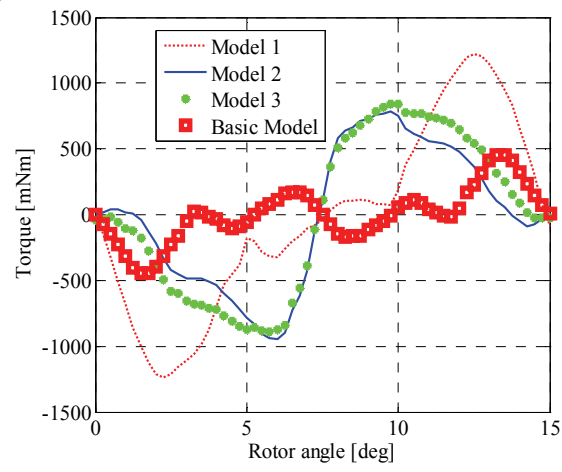

Fig. 6. a) Torque comparison, b) Cogging torque comparison 
For 3 selected geometries, the magnet angle was changed in the range: $-10 \mathrm{deg}-10 \mathrm{deg}$ in order to maximize simple additive criteria:

$$
f_{3}(x)=T_{r m s}(x)-T_{\text {cogg }}(x)
$$

Results of the second stage of optimization algorithm is presented in Table 4.

Table 4. $2^{\text {nd }}$ optimization stage results

\begin{tabular}{l|c|c|c|c|c|c|c}
\hline Model & $\begin{array}{c}\boldsymbol{x}_{\mathbf{1}}[\mathbf{m m}] \\
\text { rotor } \\
\text { outer } \\
\text { diameter }\end{array}$ & $\begin{array}{c}\boldsymbol{x}_{\mathbf{2}}[\mathbf{m m}] \\
\text { stator } \\
\text { outer } \\
\text { diameter }\end{array}$ & $\begin{array}{c}\boldsymbol{x}_{\mathbf{3}}[\mathbf{m m}] \\
\text { magnet } \\
\text { thickness }\end{array}$ & $\begin{array}{c}\boldsymbol{x}_{\mathbf{4}}[\mathbf{d e g}] \\
\text { magnet } \\
\text { angle }\end{array}$ & $\begin{array}{c}\text { Mass } \\
{[\mathbf{k g}]}\end{array}$ & $\begin{array}{c}\boldsymbol{T}_{\boldsymbol{r m s}} \\
{[\mathbf{N m}]}\end{array}$ & $\begin{array}{c}\boldsymbol{T}_{\text {cogg }} \\
{[\mathbf{N m}]}\end{array}$ \\
\hline Basic & 65.0 & 130.0 & 2 & 45 & 5.84 & 5.8 & 0.20 \\
\hline Optimal 1 - final & 69.7 & 119.0 & 2.89 & 75 & 4.96 & 7.93 & 0.31 \\
\hline Optimal 2 & 67.6 & 112.8 & 2.93 & 67 & 4.38 & 5.70 & 0.14 \\
\hline Optimal 3 & 67.2 & 111.2 & 2.77 & 64 & 4.26 & 5.32 & 0.18 \\
\hline
\end{tabular}

Figure 7a illustrates the torque for different rotor positions for the optimal, basic and final geometries. $T_{r m s}$. value is significantly increased in comparison with the basic model (36\%) while the mass was minimized (15\%). Also the cogging torque has been minimized (in average $51 \%$ ), in comparison with the $1^{\text {st }}$ optimization stage geometries, thanks to the second stage of optimization process. It is shown that a little geometry change (particularly magnet angle) may improve motor performance (decrease $T_{c o g g}$ and increasing $T_{r m s}$ ).

a)

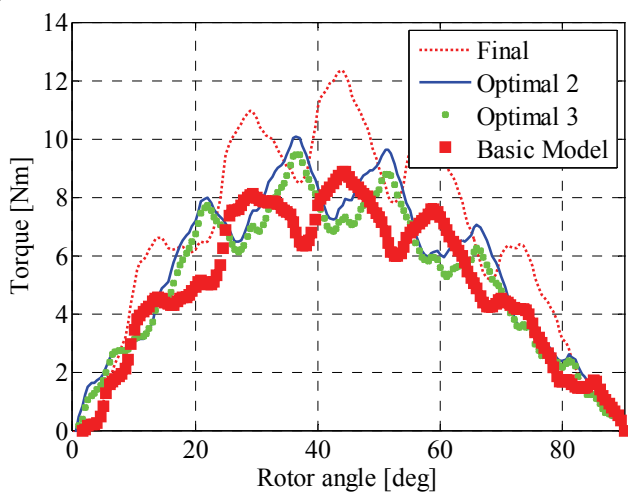

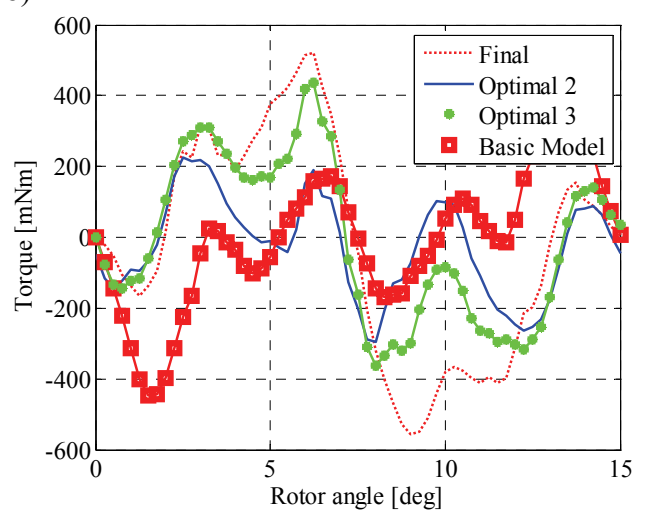

Fig. 7. a) Torque $-2^{\text {nd }}$ optimization stage, b) Cogging torque

Obtained results were verified with the 3D FE-model showing high accuracy of a $2 \mathrm{D}$ model. Differences in cogging torque and torque value may be caused by end-effects that are not considered in 2D model. Figures $8 \mathrm{a}$ and $8 \mathrm{~b}$ illustrate comparison of obtained magnetic flux density distribution for 3D and 2D geometries and Figures $9 \mathrm{a}$ and $9 \mathrm{~b}$ show torque and cogging torque comparison for final geometry. 
a)

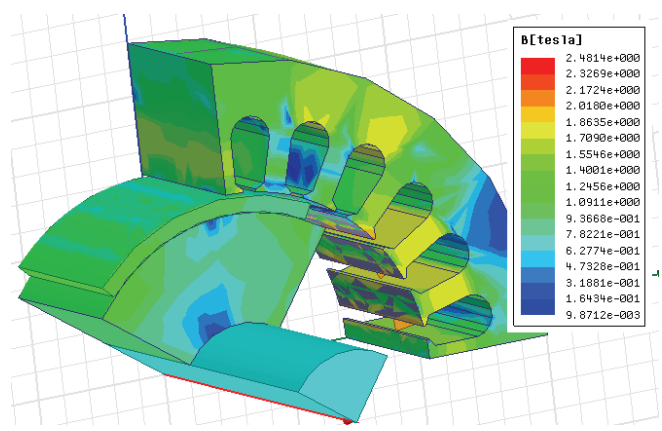

b)

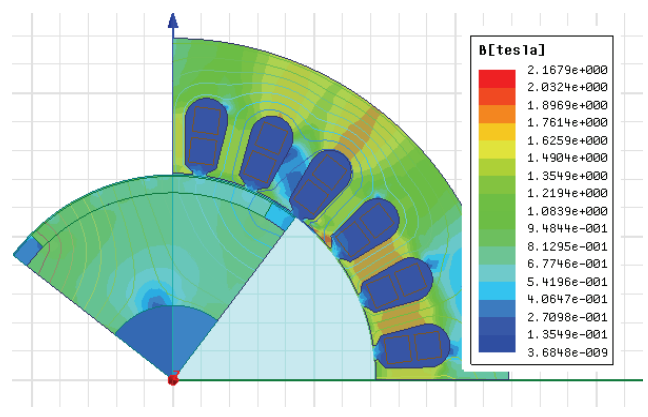

Fig. 8. a) Magnetic flux density distribution (3D optimal model), b) Magnetic flux density distribution (2D optimal model)

a)

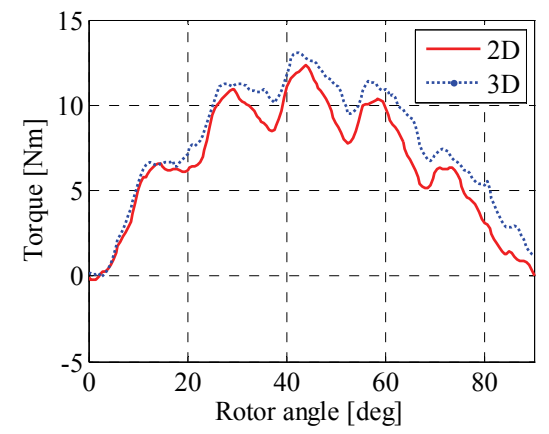

b)

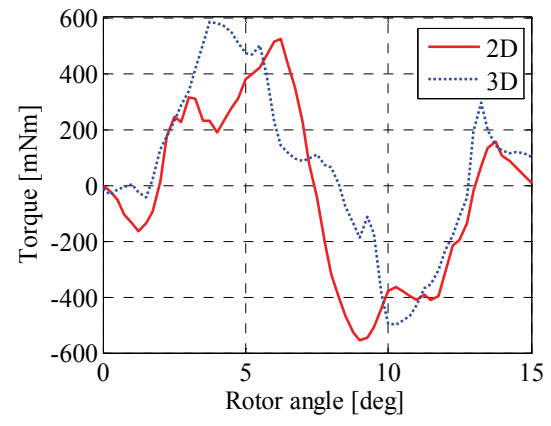

Fig. 9. a) Torque comparison - optimal model, b) Cogging torque comparison

\section{Conclusions}

It is possible to implement genetic algorithms and other customized algorithms for multiobjective motor geometry optimization process using Matlab (Mathworks) and Maxwell (ANSYS). Herein implemented algorithm with two optimization stages (GA and brute-force for best individuals) gave satisfactory results. The improvement of motor performance is significant. The simulation points out benefits of the optimization using a genetic algorithm simple and effective method. In fact, if such improvement has been possible with just four design variables, certainly, even better performance improvement will be achieved using more design variables, selected properly according to the design needs (e.g. if cogging torque reduction is of great interest, design variables could be polar shoes shape, skewing of magnets, etc.). Better optimization results could be also achieved with higher population and generation numbers.

Increasing performance of PCs affects the design process of electrical machines. Integration between optimization tools such as Matlab and FEM packages is of great interest all over 
the world. In particular, Matlab is very helpful tool in the area of different kind of optimization and data post processing; Maxwell, instead, is a well-known software for the design and the analysis of electrical machines via FEM. It is needless to emphasize that Maxwell can be also connected with Simplorer, thus whole performance of a drive system, considering control system and power electronics behavior, may be evaluated [15].

\section{Acknowledgement}

This work was supported by the Ministry of Education and Science, Poland, under grant N N510 508040.

\section{References}

[1] Di Barba P., Mognaschi M.E., Industrial design with multiple criteria: shape optimization of a permanent-magnet generator, IEEE Transaction on Magnetics 45(3): 1482-1485 (2009).

[2] Wardach M., Paplicki P., Pałka R., Cierzniewski P., Wpływ konstrukcji wirnika na parametry maszyny elektrycznej z magnesami trwatymi, Electrical Review 87(11): 131-134 (2011).

[3] May H., Pałka R., Paplicki P., Szkolny S., Wardach M., Comparative research of different structures of a permanent-magnet excited synchronous machine for electric vehicles, Electrical Review 12a: 53-55 (2012).

[4] Putek P., Slodička M., Paplicki P., Pałka R., Minimization of cogging torque in permanent magnet machines using the topological gradient and adjoint sensitivity in multi-objective design, International Journal of Applied Electromagnetics and Mechanics 39(1-4): 933-940 (2012).

[5] Di Barba P., Mognaschi M., Pałka R., Paplicki P., Szkolny S., Design optimization of a permanentmagnet excited synchronous machine for electrical automobiles, International Journal of Applied Electromagnetics and Mechanics, IOS Press 39(1-4): 889-895 (2012).

[6] Canders W.-R., May H., Pałka R., Paplicki P., Szkolny S., Modified concept of permanent magnet excited synchronous machines with improved high-speed features, Archives of Electrical Engineering 60(4): 531-540 (2011).

[7] Pałka R., Synthesis of magnetic-fields by optimization of the shape of areas and source distributions, Archiv für Elektrotechnik 75: 1-7 (1991)

[8] Sikora R., Pałka R., Synthesis of One- and Two dimensional Electrostatic Field, Archiv für Elektrotechnik 64: 105-108 (1981)

[9] Wardach M, Cogging torque reducing in electric machine by poling modification of magnetic circuit, Electrical Review 2: 131-133 (2009).

[10] Deb K., Pratap A., Agarwal S., Meyarivan T., A fast and elitist multiobjective genetic algorithm: NSGA-II, IEEE Transactions On Evolutionary Computation 6(2): 182-197 (2002).

[11] Knypiński Ł., Nowak L., Two-stage optimization of permanent magnet synchronous motor taking into account the THD factor, Scientific Papers of the Institue of Electrical Machines Drives and Measurements 32: 70-77 (2012).

[12] Paplicki P., Silniki magnetoelektryczne do hybrydowych napędów samochodowych, Electrical Review 6: 101-103 (2010).

[13] Putek P., Paplicki P., Slodička M., Pałka R., Van Keer R., Application of topological gradient and continuum sensitivity analysis to the multi-objective design optimization of a permanent-magnet excited synchronous machine, Electrical Review 88(7a): 256-260 (2012).

[14] Keyahani A., Murthy S.K., Studer C.B., Sebastian T., Study of cogging torque in permanent magnet machines, Electric Machines and Power Systems 27: 665-678 (1999).

[15] Pałka R., Paplicki P., Piotuch R., Wardach M., Simulation results of a permanent magnet synchronous motor with interior rotor which is controlled by the hysteresis current controller, Electrical Review 2b: 147-149 (2013). 